\title{
KEARNS-SAYRE SYNDROME MIGHT BE MIXED UP WITH CPEO PLUS
}

\author{
Josef Finsterer $^{1}$, Sinda Zarrouk-Mahjoub ${ }^{2}$ \\ Correspondence: fipaps@yahoo.de \\ ${ }^{1}$ Krankenanstalt Rudolfstiftung, Vienna, Austria. \\ ${ }^{2}$ University of Tunis El Manar and Genomics Platform, Pasteur Institute of Tunis, Tunisia.
}

\author{
Article History: \\ Received: May 4, 2018 \\ Accepted: March 23, 2018 \\ Published: January 1, 2019 \\ Cite this as: \\ Finsterer J, Mahjoub SZ. Kearns- \\ sayre syndrome may be mixed up \\ with cpeo plus. Malang \\ Neurology Journal; 2019.5:46-7. \\ DOI: \\ http://dx.doi.org/10.21776/ub.mnj \\ .2019 .005 .01 .8
}

\section{ABSTRACT}

In a recent article, Al Ghamdi presented a 40yo parturient with Kearns-Sayre syndrome (KSS) who had received an implantable cardioverter defibrillator (ICD) because of an AVblock II (Mobitz 2 (2:1)) 11y earlier and underwent caesarean delivery for preeclampsia in local anesthesia with bupivacaine and fentanyl. ${ }^{1}$ We have the following comments and concerns.

Keywords: Mitochondrial, Kearns-Sayre syndrome, mtDNA, seizures, stroke-like episodes, phenotype, genotype, multisystem disease, lactic acidosis

\section{Introduction}

The main disadvantage of the report is that the genetic diagnosis was not provided. Was KSS due to a mtDNA deletion, which is the case in the vast majority of the cases, or was it due to a single mtDNA or nDNA mutation? In addition to mtDNA deletions, KSS has been reported due to the variants $\mathrm{m} .3243 \mathrm{~A}>\mathrm{G}$ (tRNA(Leu) ${ }^{2}$ and $\mathrm{m} .3249 \mathrm{G}>\mathrm{A}$ $(\operatorname{tRNA}(\mathrm{Leu})){ }^{3}$ As long as the clinical diagnosis has not been confirmed genetically, it remains questionable if KSS was the correct diagnosis or if the patient was a KSS mimic. Arguments against KSS are that the patient was already 40 years old, that she had given birth to three children, and that she obviously had neither ataxia nor limb muscle weakness, hypoacusis, renal insufficiency, endocrine abnormalities, or cognitive decline. ${ }^{1}$ Thus, it is conceivable that the patient did not have KSS but rather a CPEO-plus syndrome, which usually has a better life expectancy and prognosis than KSS.

A further objective is that no extensive family history was taken. Though KSS follows a maternal trait of inheritance in only $4 \%$ of the cases, [4poultin] it is nonetheless important for the family planning and the genetic counselling if the mutation occurred sporadically or was inherited. Did the three children or other first degree relatives of the index case ever develop phenotypic features of a mitochondrial disorder (MID)?

In a series of 35 patients with KSS, 4 died from sudden cardiac death (SCD). ${ }^{5}$ In this respect it would be interesting to know how often the ICD had deployed since implantation, and in case it had deployed which type arrhythmias had triggered the shock. Did the patient ever complain about palpitations or a syncope or pre-syncope since implantation of the ICD?
Another point missing in the description is the current medication of the patient. Though pregnant, it cannot be excluded that she was under long-term medication for example with coenzyme-Q, which has been shown to be beneficial for some aspects of the phenotype. Did the patient receive any long-term medication, particularly cofactors, antioxidants, or vitamins? Did the patient adhere to a ketogenic diet, which has been shown to be beneficial in some of the MIDs?

Patients with a MID may not only develop adverse reactions to volatile anesthetics but also to local anesthetics, such as articaine or ropivacaine. Did the index case develop any adverse reactions, such as muscle weakness, respiratory distress, or fatigue to bupivacaine?

\section{Conclusion}

Overall, this interesting case requires confirmation of the diagnosis by genetic investigations, provision of a thorough family history, information about the current medication, and about the function of the ICD. Additionally, results of echocardiography should be provided since CPEO-plus, KSS, or multisystem MIDs (MIMODS) may phenotypically manifest with cardiomyopathy.

\section{References}

1. Al Ghamdi A. Anesthetic management of a parturient with Kearns-Sayre syndrome, dual-chamber and VVI implantable defibrillator pacemaker/defibrillator, and preeclampsia for cesarean delivery: A case report and review of the literature. Saudi J Anaesth; 2018.12:1348. DOI: 10.4103/sja.SJA_630_17 
2. Yu N, Zhang YF, Zhang K, Xie Y, Lin XJ, Di Q. Melas and Kearns-Sayre overlap syndrome due to the mtDNA m. A3243G mutation and large-scale mtDNA deletions. eNeurologicalSci; 2016.4:15-18

DOI: 10.1016/j.ensci.2016.04.006

3. Seneca S, Verhelst H, De Meirleir L, Meire F, Ceuterick-De Groote C, Lissens W, Van Coster R. A new mitochondrial point mutation in the transfer RNA (Leu) gene in a patient with a clinical phenotype resembling Kearns-Sayre syndrome. Arch Neurol;
2001.58:1113-8.

PubMed: https://www.ncbi.nlm.nih.gov/pubmed/11448301

4. Poulton J, Finsterer J, Yu-Wai-Man P. Genetic counselling for maternally inherited mitochondrial disorders. Mol Diagn Ther; 2017.21:419-429. DOI: 10.1007/s40291-017-0279-7

5. Khambatta S, Nguyen DL, Beckman TJ, Wittich CM. Kearns-Sayre syndrome: a case series of 35 adults and children. Int J Gen Med; 2014.7:325-32. DOI: 10.2147/IJGM.S65560 